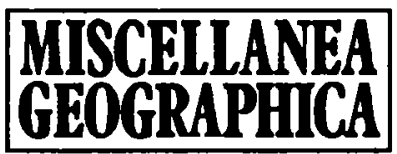

WARSZAWA 1994 Vol. 6

Krzysztof Olszewski

\title{
THERMAL EFFECTS OF THE AIR MASSES TRANSFORMATION
}

Circulation factors play an important role in shaping weather and climatic conditions at moderate geographical latitudes since within this zone the greatest variability of pressure systems and the ensuing differentiation of the air masses are observed. The change of their physical properties is one of the reasons for changes of the air temperature. These changes depend in the first place on the kind of the air mass (Olszewski 1988), that is on the location of the area of its origin. Of importance are the road and velocity of transfer of the mass from the area which determines its transformation, that is change of physical properties. Transformation of the air mass is usually understood as changes in temperature and humidity. The extent and intensity of these changes depend on the type of land over which the air passes, as well as on the time of its travel from the area of its origin. Some information on the extent of thermal transformation may be provided by the analysis of changes in the successive twenty four hours' periods of prevalence of the same type of the air mass.

This paper has been based on the material from the meteorological station of the Institute of Meteorology and Water Management at WarszawaOkęcie (1956-1960). It has been investigated how the twenty-four hours' course of the air temperature changes, depending on the duration of occurrence of the air masses, which reflects degree of transformation to some extent. The analysis focused on the cases when the given type of the air mass persisted for several days incessantly. The largest number of days was distinguished when the air mass persisted for three days. The three-day periods were analyzed in the particular seasons: winter, spring, summer, autumn (Fig. 1).

The most intensive changes in temperature in the course of the successive days can be observed in the polar continental air mass. During its persitence the air temperature changes during twenty-four hours from 0.48 to $1.44 \mathrm{deg}$ (Table 1). Such changes in the polar maritime air mass are smaller, the rate of temperature changes ranging from 0.12 to $0.48 \mathrm{deg}$ per day. Direction of trend in the particular polar masses varies according to the season of the year. In winter, when the mass $\mathrm{cP}$ prevails, the air 

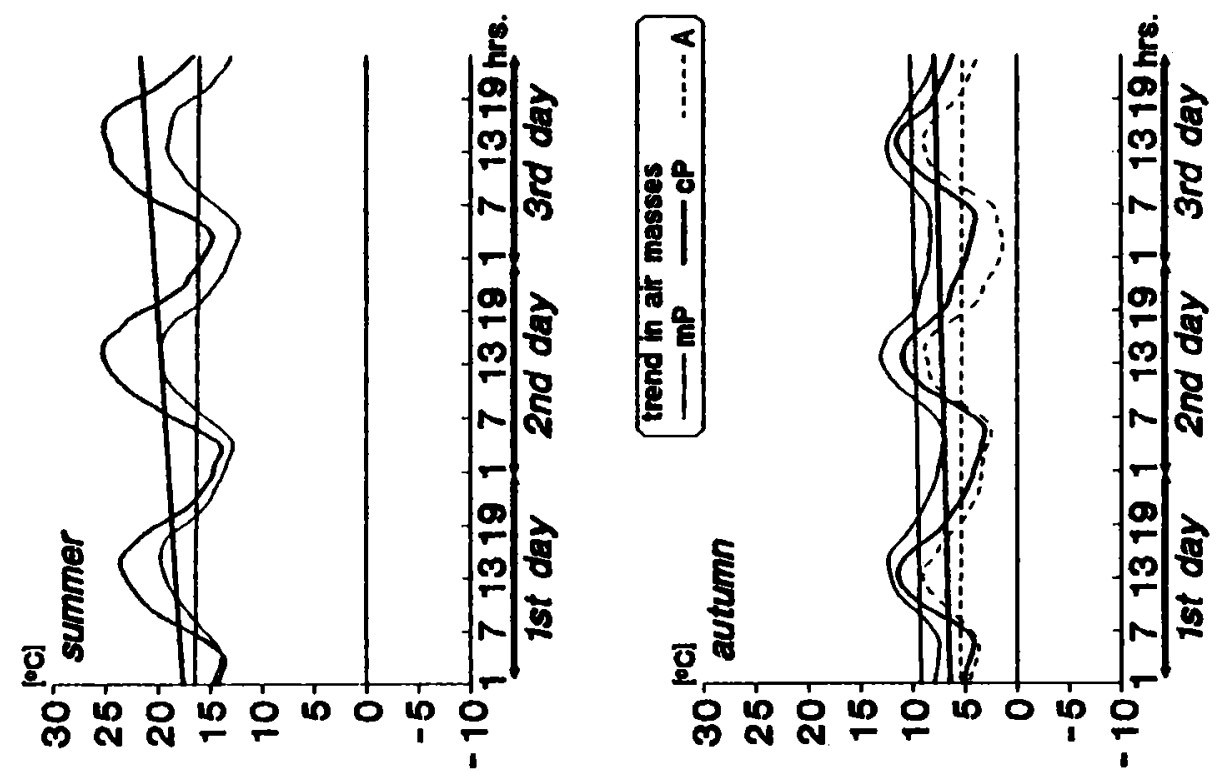

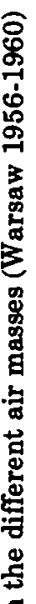
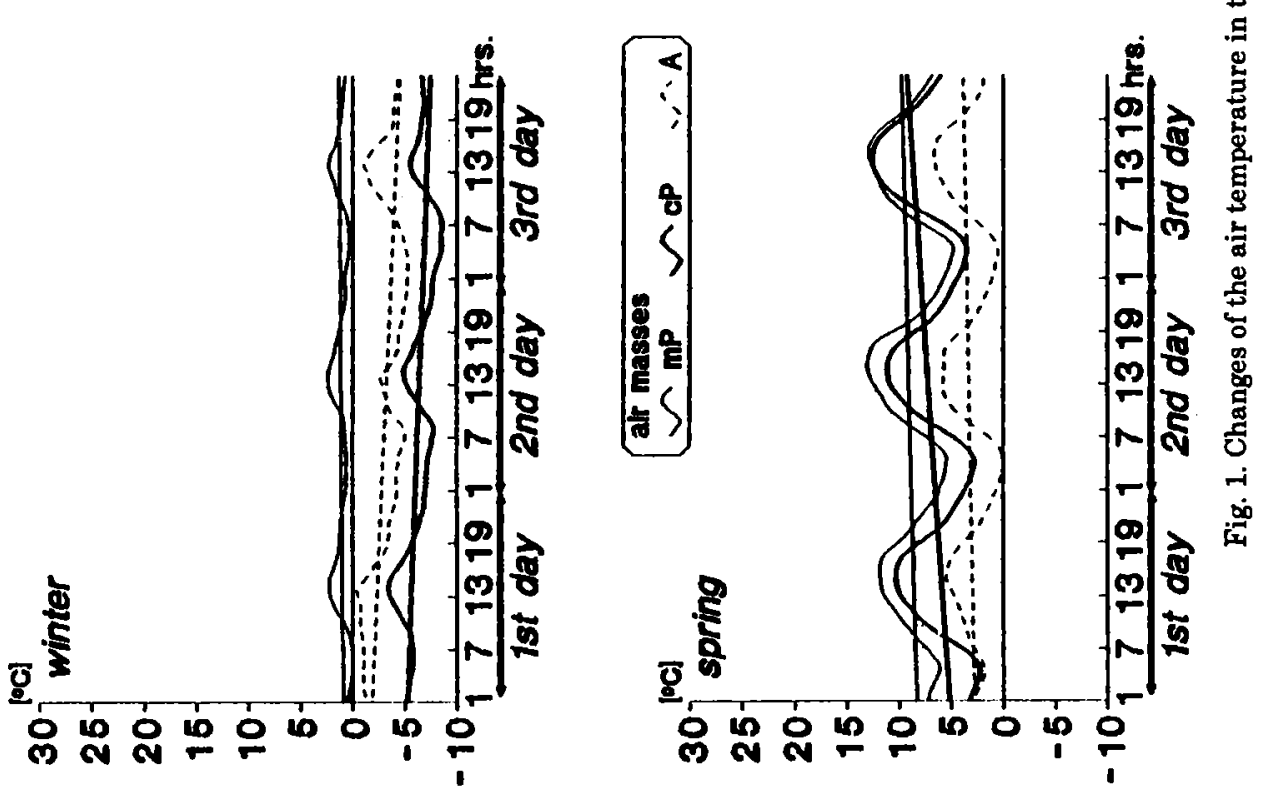
temperature drops during the successive days $(-0.72 \mathrm{deg} /$ day $)$, while in $\mathrm{mP}$ there is a slight increase $(0.12 \mathrm{deg} / \mathrm{day})$. The winter transformation is particularly conspicuous in the cool air masses carried from the eastern direction (Zverev 1965). Cloudless and windless weather often leads to creation of ground layer of extremely cool air. Under such conditions, during one night the temperature may drop by 10-15 deg; at subsequent nights changes are already slower. This is clearly revealed in the mean daily courses. During the first two days, the air temperature declines considerably (by about 5 deg on the average), while during the third day the intensity of the fall is already smaller. Generally speaking, it indicates that transformation of the air masses in the winter season is strongest, and that its intensity depends on the initial thermal conditions of the air mass. That is why in much warmer masses flowing from the western sector, there is an increasing trend of the air temperature, the rate of warming amounting to $0.2 \mathrm{deg} / \mathrm{day}$.

Table 1

Coefficients of the line of regression (y)

\begin{tabular}{|l|c|c|c|c|}
\hline \multirow{2}{*}{ season } & air mass & \multicolumn{2}{|c|}{$y=\mathrm{ax}+\mathrm{b}$} & trend \\
\cline { 2 - 5 } & & $\mathrm{a}$ & $\mathrm{b}$ & (deg/day) \\
\hline \multirow{3}{*}{ winter } & $\mathrm{mP}$ & 0.005 & 0.88 & 0.12 \\
& $\mathrm{cP}$ & -0.030 & -5.19 & -0.72 \\
& $\mathrm{~A}$ & -0.040 & -1.86 & -0.96 \\
\hline \multirow{3}{*}{ spring } & $\mathrm{mP}$ & 0.200 & 8.30 & 0.48 \\
& $\mathrm{cP}$ & 0.060 & 5.07 & 1.44 \\
& $\mathrm{~A}$ & 0.010 & 2.75 & 0.24 \\
\hline summer & $\mathrm{mP}$ & -0.010 & 16.42 & -0.24 \\
& $\mathrm{cP}$ & 0.060 & 17.54 & 1.44 \\
\hline \multirow{3}{*}{ autumn } & $\mathrm{mP}$ & 0.010 & 9.20 & 0.24 \\
& $\mathrm{cP}$ & 0.020 & 6.38 & 0.48 \\
& $\mathrm{~A}$ & -0.033 & 5.42 & -0.07 \\
\hline
\end{tabular}

Note: $y$ - air temperature; $x$ - hours of the day

In summer the temperature increase in the successive days can be observed in the polar continental mass (1.44 deg/day), while its decline is to be found in the polar maritime mass $(-0.24 \mathrm{deg} /$ day $)$. The more intensive temperature changes in the mass $\mathrm{cP}$ may be due to its lesser cloudiness (Olszewski 1990). Thus the flow of solar radiation is more intensive which results in a more rapid rate of temperature increase on the successive days.

In the transition seasons of the year, that is in spring and autumn, the two types of the polar mass reveal the growing trend of temperature; it is higher in $\mathrm{cP}$ than in $\mathrm{mP}$. Since in these seasons the $\mathrm{mP}$ mass is warmer than $\mathrm{cP}$, more intensive transformation changes occur in the cooler air which flows over the warmer ground. The rate of temperature changes usually ranges from 0.2 to $0.5 \mathrm{deg} / \mathrm{day}$. 
This analysis shows that the air mass is not homogeneous and that during the successive days of its prevalence over the given area it exhibits changes in thermal properties. The changes are related not only to the daily course of atmospheric processes but also to the character of the ground over which the air is transferred. This varied character of the ground differentiates i.a. thermal properties of the air mass on the successive days of its persistence over a given area.

\section{REFERENCES}

Olsz e w s ki K., 1988, "Diurnal changes of the air temperature in different air masses", Miscellanea Geographica, Warszawa.

$01 \mathrm{sz}$ ew ski K., 1990, "The role of air mass types in shaping twenty four hours' variations in cloudiness", Miscellanea Geographica, Warszawa.

Zverev A.S., 1965, Meteorologia synoptyczna (Synoptic Meteorology), Warszawa. 